\title{
The plastic surgeon and the anesthetist
}

$T_{\text {we }}^{\text {her }}$ hey keep our patients safe during surgery. Without them we could not do the things we do. Or could we?

Hospitals have one goal - the bottom line. Money is limited; how much can we do with what we have? Sounds admirable.

So, we are doing economical surgery. We are doing hand surgery without a tourniquet, using lidocaine and adrenaline. We do tendon and nerve surgery in the minor surgery room, things we were taught to do in the main operating room under the most expensive circumstances.

Why? Because we have to - it's the bottom line again.

We are becoming delivery innovators and enjoying it. We are doing hand surgery without an assistant, using surgical tricks to hold flaps to expose the wound. All this is telling us that despite the affluence of our society, we are not as well off as we think; we have a determination to cut waste and duplication.

Somewhere there is a health czar saying, "I wonder how cheaply we could do this?"

"Lets turn the screws some more and see if anybody complains."

The United States has nurse anesthetists. In Canada, we have general practitioner (GP) anesthetists. We also have anesthesiologists but the name designation is not important to anyone. Perhaps anesthesiologists will only be at university hospitals, teaching both streams of physicians.

The emergence of GP anesthetists is due to the declining number of physicians entering anesthesiology, and it gives the GP a more diverse career. Modern, short-acting drugs have revolutionized anesthesia, and made it safer and easier. Laryngeal masks are easier to use than endotrachial tubes.

Still, the key to good care is communication among operating room staff. Everything must be directed to the patient's safety and reviewed with check lists. If everything is not ready, surgery should be postponed until it is. There must be no antagonism among operating room staff.The operating room is no place for bad communication or the silent treatment. It is no place for personal phone calls or loud music. Everyone must be receptive to listening and signals focused on the patient. No one should ever have to raise their voice to be heard. If you can't talk and operate, don't talk.

The surgeon is no longer captain of the ship; operating rooms are group efforts, but the surgeon is still the one making most of the decisions about what is done and what is needed. Everyone needs to listen so that he or she knows the message has been received, and the suture or instrument needed is being retrieved. Talk about trivial subjects needs to be minimized or saved for the coffee room, and this takes discipline from everybody.

What works in the modern operating room is for everyone's effort to be appreciated. This is done by saying so immediately. When everyone's effort is not appreciated, it is recognized by saying nothing or by saying, "folks, I just need to focus now, so could you save this discussion for later?" Internalizing does not work, it just raises blood pressures. The word gets around that you are having a bad day. Never let this happen. Prevent it, or fix it right away. As a surgeon, remember the people around you are far less interested in the operation than you are, although you are likely to hear remarks such as, "what is he/she having this done for?" You may or may not be able to stoke their interest.

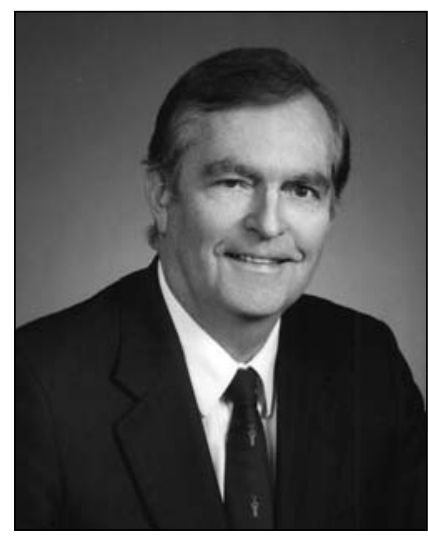

John R Taylor
Plastic surgeons know more anesthesia than any other kind of surgeon. This is because we can do anesthesia too, and we do. We give dissociative anesthesia, to make it comfortable to give lidocaine. We have by far the greatest experience of any surgical specialty of giving our own anesthesia except perhaps dentistry and oral surgery. Our trainees should take the opportunity every time they are in the operating room to absorb everything they can about monitoring, tubes and drugs given.

There is a movement that believes that patients suffer pain unnecessarily, and that narcotics for pain do not cause addiction (as long as pain is present).

With experience it came as a surprise to me that with certain exceptions (renal colic, myocardial infarction and endstage cancer), postoperative pain is largely suggestible.

By this I mean: if I say, "You will have some pain today, so don't be brave, take your pills, but no pain tomorrow", then this is what will happen. But I have to say it in a certain way, and I have to bring up the pain subject myself and be authoritative. I have to say, pain is a sign. If you have pain that increases, I want you to call me and tell me, I want to know. Pain means something. If you have no pain, everything is fine. Patients have to know they do not have to be brave. So I prescribe far less analgesia than younger physicians and less potent drugs too. I do not rely on the drug, I rely on what I say, and if it is understood and believed.

All this leads to a faster recovery, a patient with a clear head after surgery, a pleasantly surprised family and more referrals. Patients need to know you are in charge, no matter how society spreads responsibility.

Let's treasure our anesthesia colleagues and learn everything we can from them.

Our patients will benefit and so will we.

John R Taylor 